Research article

\title{
Beneficial impact of phosphate solubilizing fungi on growth of Saraca asoca (Roxb.) de Willd. under nursery condition
}

\author{
Soumya Ranjan Nayak, Manas Ranjan Panigrahi and Nibha Gupta*
}

Plant Pathology and Microbiology Division, Regional Plant Resource Centre, Bhubaneswar -751015 Odisha

*Corresponding Author: nguc2003@yahoo.co.in

[Accepted: 12 June 2017]

\begin{abstract}
Saraca asoca belonging to family Caesalpinaceae commonly known as 'Sita Ashok', and assessed as endangered; and important indigenous plant of India and the state flower of Odisha. S. asoca is a medicinal plant that claims to cure several diseases according to Ayurvedic medicine. A study was conducted to investigate the effects of phosphate solubilizing fungi on the growth \& establishment of Saraca asoca under nursery condition. Five phosphate solubilizing fungi were supplemented on Saraca asoca seedlings separately and their effects on morphological and physiological growth parameters were recorded. Inoculation of fungal culture Aspergillus kanagawaensis showed significant improvement in shoot height, root length and leaf number and Aspergillus japonicus developed the highest number of branches, Aspergillus niger showed highest leaf area. Overall, application of fungal culture Aspergillus kanagawaensis and Aspergillus niger resulted in increased biomass production as compared to control experimental sets.
\end{abstract}

Keywords: Phosphate solubilization - Aspergillus - Forest - Saraca asoca - Bioinoculant.

[Cite as: Nayak SR, Panigrahi MR \& Gupta N (2017) Beneficial impact of phosphate solubilizing fungi on growth of Saraca asoca (Roxb.) de Willd. under nursery condition. Tropical Plant Research 4(2): 242-245]

\section{INTRODUCTION}

Saraca asoca (Roxb.) de Willd. is an indigenous medium sized evergreen tree belonging to the family Caesalpinaceae with several vernacular names such as, Ashoka, Sita Ashok (Hindi), Shabuqa (Arabic), Kankeli (Sanskrit) and Ashokadamara (Kannada) (Sharma et al. 2005, Anitha et al. 2008). Saraca asoca is one of the important indigenous medicinal plants and found throughout India (Bajpai et al. 2016, Deepa et al. 2016, Bisht et al. 2017). Almost every part of the plant is medicinal and it has been a part of ayurvedic medicine for centuries, known to have anti-cancer, anti-hemorrhagic, anti-oxidant, anti-oxytocic and anti-microbial activities (Nadkarni et al. 2005, Pradhan et al. 2009). The plant is under great threat due to management practices, increasing demand for its phytochemicals, poor seed viability and overexploitation of the plant for its bark, flower, seeds etc.; which has resulted in the dwindling of its population throughout the globe (Pushpangadan et al. 2004). Bioinoculation of beneficial like phosphate solubilizing fungi may play a vital role in plant growth and development: The role of such bio-inoculants in breaking seed dormancy through plant growth promoting substances also had been reported (Chaukiyal et al. 2000, Chopade et al. 2008). Since, S. asoca has also enlisted in RET list, its propagation, conservation has to gain priority due to its remarkable medicinal value (Chopade et al. 2008). So the experiment was carried out to evaluate the impact of some phosphate solubilizing fungi on Saraca asoca in nursery condition for better establishment and growth.

\section{MATERIALS AND METHODS}

The brownish to deep brown colored seeds were decapsulated and germinated. Seedlings of 30 days were transplanted into the poly bags containing fumigated soil. Six different phosphate solubilisng fungal isolates (confirmed earlier through plate culture test performed on Pikovskaya' medium) identified as Aspergillus kanagawaensis, Penicillium citrinum, Aspergillus japanicus, Aspergillus niger, Fusarium oxysporum were used for the experiment. The seven day old culture developed in Sabouraud Dextrose broth at $30^{\circ} \mathrm{C}$ were inoculated (@100 ml per poly bag) separately \& thrice with monthly interval. Un-inoculated plants, autoclaved inoculated cultures were considered as control and treated control, respectively. Regular watering was done to keep the 
plants healthy. Finaldata was recorded on $140^{\text {th }}$ day for Plant height, fresh and dry biomass, root-shoot ratio, physiological growth parameter like relative growth rate, net assimilation rate, leaf area ratio, quality index, were calculated Dori et al. (1990).

RESULTS AND DISCUSSION

Table 1. Growth performance of Saraca asoca seedling under different treatment.

\begin{tabular}{|c|c|c|c|c|c|c|c|c|}
\hline \multirow[b]{2}{*}{ Treatment } & \multirow{2}{*}{$\begin{array}{l}\text { Shoot } \\
\text { Height } \\
(\mathrm{cm})\end{array}$} & \multirow{2}{*}{$\begin{array}{l}\text { Root } \\
\text { Length } \\
(\mathrm{cm}) \\
\end{array}$} & \multirow{2}{*}{$\begin{array}{l}\text { No. of } \\
\text { leaves }\end{array}$} & \multirow{2}{*}{$\begin{array}{l}\text { Leaf Area } \\
\left(\mathrm{mm}^{2}\right)\end{array}$} & \multicolumn{2}{|c|}{ Wet Biomass(g) } & \multicolumn{2}{|c|}{ Dry Biomass(g) } \\
\hline & & & & & Shoot & Root & Shoot & Root \\
\hline Control & $30.4 \pm 6.3$ & $20.6 \pm 5.9$ & $25.4 \pm 13.2$ & $2645.6 \pm 196.1$ & $12.328 \pm 6.5$ & $8.069 \pm 5.0$ & $6.062 \pm 2.9$ & $3.248 \pm 1.5$ \\
\hline Aspergillus kanagawaensis & $45.4 \pm 13.8$ & $24.9 \pm 6.7$ & $49.1 \pm 9.9$ & $7955.4 \pm 328.8$ & $27.719 \pm 13.1$ & $10.564 \pm 3.9$ & $12.832 \pm 5.3$ & $5.104 \pm 2.0$ \\
\hline Aspergillus kanagawaensis TC & $25.3 \pm 4.2$ & $24.3 \pm 2.1$ & $28.7 \pm 2.1$ & $2408 \pm 347.6$ & $15.627 \pm 2.0$ & $9.753 \pm 0.6$ & $9.221 \pm 2.1$ & $5.110 \pm 0.5$ \\
\hline Penicillium citrinum & $22.3 \pm 4.7$ & $17.9 \pm 2.9$ & $14.9 \pm 7.5$ & $4414.4 \pm 185.2$ & $4.657 \pm 2.7$ & $3.874 \pm 1.8$ & $1.847 \pm 1.2$ & $1.506 \pm 0.9$ \\
\hline Penicillium citrinum $\mathrm{TC}$ & $26.0 \pm 2.0$ & $14.3 \pm 2.3$ & $10.3 \pm 2.1$ & $2877 \pm 327.8$ & $1.602 \pm 0.8$ & $2.791 \pm 0.4$ & $0.606 \pm 0.3$ & $0.819 \pm 1.6$ \\
\hline Aspergillus japanicus & $26.3 \pm 7.4$ & $15.6 \pm 3.5$ & $32.9 \pm 14.0$ & $4404.8 \pm 356.1$ & $11.753 \pm 4.7$ & $7.102 \pm 5.1$ & $4.805 \pm 1.9$ & $2.522 \pm 1.5$ \\
\hline Aspergillus japanicus TC & $23.3 \pm 3.5$ & $16.0 \pm 1.0$ & $28.7 \pm 9.1$ & $2190 \pm 130.6$ & $8.536 \pm 2.6$ & $6.730 \pm 3.0$ & $3.735 \pm 1.6$ & $2.715 \pm 0.8$ \\
\hline Aspergillus niger & $38.3 \pm 6.2$ & $19.0 \pm 4.3$ & $42.3 \pm 9.6$ & $9051.4 \pm 3050.1$ & $20.645 \pm 5.8$ & $8.278 \pm 1.9$ & $9.601 \pm 2.8$ & $4.120 \pm 1.3$ \\
\hline Aspergillus niger TC & $28.0 \pm 10.6$ & $19.7 \pm 5.0$ & $26.0 \pm 20.5$ & $3291 \pm 659.5$ & $12.567 \pm 7.1$ & $8.942 \pm 8.5$ & $5.603 \pm 3.6$ & $2.697 \pm 0.4$ \\
\hline Fusarium oxysporum & $24.3 \pm 5.4$ & $18.1 \pm 3.7$ & $21.8 \pm 11.1$ & $5015 \pm 163.6$ & $11.404 \pm 6.2$ & $5.357 \pm 2.4$ & $4.750 \pm 2.4$ & $2.057 \pm 1.0$ \\
\hline Fusarium oxysporum TC & $24.3 \pm 5.5$ & $17.0 \pm 1.0$ & $13.3 \pm 6.0$ & $2833 \pm 397.9$ & $3.842 \pm 1.3$ & $3.181 \pm 1.4$ & $1.689 \pm 0.9$ & $1.333 \pm 0.9$ \\
\hline
\end{tabular}

Note: $\mathrm{TC}=$ Treated Control.

A different pattern of plant growth was observed in different treatments as well as un-inoculated control and treated control. The data of shoot height, root length of seedlings in the nursery at un-inoculated control, inoculated heat treated control and treated seedlings are depicted the prominent and significant differences among the treatments and it was higher in plants treated with Aspergillus kanagawaensis and Aspergillus niger (Table 1). Aspergillus japanicus illustrated highest number of branches. Aspergillusniger treated plants showed a significant difference in leaf area. Aspergillus kanagawaensis and Aspergillus niger exhibited growth promoting effect over control and treated control as far as shoot height, leaf number, leaf area and plant biomass is concerned. Differences root lengths were not reflected in all control and inoculated plants. Inoculation of Aspergillus kanagawaensis was found to be best in enhancing shoot fresh and dry biomass over other treatments as well as control\& treated control. The inoculation of phosphate solubilizing fungi Penicillium citrinum, Fusarium oxysporum \& Aspergillus japanicus also yielded good leaf growth (leaf area) as compared to control and treated control plants. Aspergillus kanagawaensis showed a better change in Relative growth rate (RGR) and Net assimilation rate (NAR) was also changed due to the enhancement in dry biomass (Table 2).

Table 2. Physiological growth performance of Saracaasoca under pot culture condition.

\begin{tabular}{|c|c|c|c|c|c|c|c|c|c|c|c|}
\hline \multirow[t]{2}{*}{ Prameters } & \multirow[t]{2}{*}{ Control } & \multicolumn{2}{|c|}{$\begin{array}{l}\text { Aspergillus } \\
\text { kanagawaensis }\end{array}$} & \multicolumn{2}{|c|}{$\begin{array}{l}\text { Penicillium } \\
\text { citrinum }\end{array}$} & \multicolumn{2}{|c|}{$\begin{array}{l}\text { Aspergillus } \\
\text { japanicus }\end{array}$} & \multicolumn{2}{|c|}{$\begin{array}{l}\text { Aspergillus } \\
\text { niger }\end{array}$} & \multicolumn{2}{|c|}{$\begin{array}{l}\text { Fusarium } \\
\text { oxysporum }\end{array}$} \\
\hline & & $\mathbf{L C}$ & $\mathbf{A C}$ & $\mathbf{L C}$ & $\mathbf{A C}$ & LC & $\mathbf{A C}$ & LC & $\mathbf{A C}$ & $\mathbf{L C}$ & $\mathbf{A C}$ \\
\hline Wet RGR $\left(\mathrm{d}^{-1)}\right.$ & 0.117 & 0.288 & 0.153 & 0.031 & 0.003 & 0.110 & 0.074 & 0.209 & 0.119 & 0.106 & 0.022 \\
\hline Dry RGR $\left(\mathrm{d}^{-1}\right)$ & 0.060 & 0.135 & 0.095 & 0.013 & 0.001 & 0.046 & 0.034 & 0.099 & 0.055 & 0.045 & 0.011 \\
\hline $\operatorname{NAR}\left(\mathrm{g} \cdot \mathrm{m}^{-2} \cdot \mathrm{d}^{-1}\right)$ & 60.75 & 853.92 & 73.89 & 35.99 & 1.08 & 127.10 & 19.02 & 735.39 & 90.84 & 152.97 & 13.44 \\
\hline $\operatorname{LAR}\left(\mathrm{m}^{2} \cdot \mathrm{g}^{-1}\right)$ & 0.63 & 0.71 & 0.41 & 2.39 & 3.49 & 1.10 & 0.86 & 1.04 & 0.78 & 1.22 & 1.88 \\
\hline QI & 0.289 & 0.374 & 0.529 & 0.143 & 0.053 & 0.260 & 0.261 & 0.338 & 0.276 & 0.256 & 0.118 \\
\hline RSR & 0.678 & 0.548 & 0.960 & 0.803 & 0.550 & 0.593 & 0.687 & 0.496 & 0.704 & 0.745 & 0.700 \\
\hline
\end{tabular}

Note: $\mathrm{LC}=$ Live Culture, $\mathrm{AC}=$ Autoclaved Culture.

In view to evaluate the effective plant growth promoting ability of phosphate solubilizing fungion forest trees, present experiment was set up on Saracaasoca in pot culture conditionwhich was supplemented with liquid cultures of phosphate solubilising fungi namely: Aspergillus kanagawaensis, Penicillium citrinum, Aspergillus japanicus, Aspergillus niger, Fusarium oxysporum. The different fungal strains used in the present study were having phosphate solubilising potential tested in plate culture method in laboratory earlier. Odee $e t$ al. (2002) recommended inoculation of liquid cultures to raise the healthy seedlings in the nursery conditions. This also helps in increasing fungal population in the rhizosphere and finally mineral solubilisation. The costly affair of chemical fertilizers, as well as limited supply of nutrient to the plants, demands an alternative like mineral solubilising microbes. The enhancement in the growth of Saraca asoca in pot culture conditions in the present experiment revealed the effect of fungal inoculation and their usefulness as bioinoculants for plant 
productivity. Experimental seedling of Saracaasoca supplied with different fungal cultures had exhibited good growth in terms of plant height and biomass. Under experimental conditions Aspergillus kanagawaensis was found to be very effective in increasing over all plant growth including shoot height, root length, number of branches, no of leaves, leaf area and biomass. However, Aspergillus niger was also prominent in increasing leaf area of the plants. Another fungal culture namely Aspergillus japanicus was able to increase branch numbers.

The experimental plants were surviving and growing well even after 140 days without any further addition of chemical fertilizers indicate its role towards seedlings establishment after transfer and subsequent growth (Maliha et al. 2004, Hossain et al. 2007, Nenwani et al. 2010) . Manyfungi like Penicillium and Aspergillus etc. were reported as phosphate solubilisers as well as evaluated for the plant growth and productivity (Dash et al. 2013, Vibha et al. 2014). Present study also confirms these findings as inoculation of Aspergillus kanagawaensis and Penicillium citrinum into the rhizosphere of S. asoca seedlings were found to be effective in enhancing and improving plant growth in terms of LAR and RSR. The carbon assimilation and allocation may be reflected in the trait of LAR as well as growth variation may be due RGR and NAR Krishnan \& Satakappam (2009). Significant differences in plant's physiological parameters like relative growth rate, net assimilation rate and leaf area ratio were observed in inoculated and uninoculated seedlings. However, data recorded through present study will be helpful in the development of bioinoculants of Aspergillus kanagawaensis, Aspergillus niger for the mass scale propagation of $S$. asoca for commercial use as thistree species is a good source of medicinal compounds.

\section{CONCLUSION}

From the above experiment conducted to evaluate the application of phosphate solubilizing potential of selected fungal strains in Saraca asoca was successful and the plants show tremendous growth and development as compare to controls. This concludes the effectiveness of fungal microbes and endophytic activity with plant root system. Further study and research has to be needed so as to confirm the fungal diversity's adaptation with other forest trees which are more prone to be endangered.

\section{ACKNOWLEDGMENTS}

Authors acknowledge the financial assistance obtained from Forest and Environment Dept., Govt. of Odisha through State Plan project 2015-16.

\section{REFERENCES}

Anitha B, Mohan VR, Athiperumalsami T \& Suthaa S (2008) Ethnomedicinal plants used by the Kanikkars of Tirunelveli District, Tamil Nadu, India to treat skin diseases. Ethnobotanical leaflets 12: 171-180.

Bajpai O, Pandey J \& Chaudhary LB (2016) Ethnomedicinal uses of tree species by Tharu tribes in the Himalayan Terai region of India. Research Journal of Medicinal Plant 10(1): 19-41.

Bisht A, Irshad S, Rawat AKS, Dwivedi H (2017) Pharmacognostical studies on Saraca asoca (Roxb.) Willd. flower. Tropical Plant Research 4(1): 153-160.

Chaukiyal SP, Sheel SK \& Pokhriyal TC (2000) Effects of seasonal variation and nitrogen treatments on nodulation and nitrogen fixation behaviour in Pongamia pinnata. Journal Tropical Forest Sciences 12: 357368.

Chopade VV, Tankar AN, Pande VV, Tekade AR, Gowekar NM, Bhandari SR \& Khandake SN (2008). Pongamia pinnata: Phytochemical constituents, traditional uses and pharmacological properties. A review International Journal Green Pharmacy 2: 72-75.

Dash S, Mohapatra AK \& Gupta N (2013) Growth response of Dalbergia sissoo Roxb. To mineral solubilizing bacteria and fungi in nursery conditions.Tropical Ecology 54(1): 109-115.

Deepa MR, Sheema Dharmapal P \& Udayan PS (2016) Floristic diversities and medicinal importance of selected sacred groves in Thrissur district, Kerala. Tropical Plant Research 3(1): 230-242.

Dori S, Solel Z, Kashman Y \& Barash I (1990) Characterization of hydroxamatesiderophores and siderophore mediated iron uptake in Gaeumannomyces graminis var. tritici. Physiological and Molecular Plant Pathology 37: 97-106.

Hossain M, Sultana F, Kubota M, Koyama H \& Hyakumachi M (2007) The plant growth promoting fungus Penicillium simplicissimum GP17-2 induces resistance in Arabidopsis thaliana by activation of multiple defence signals. Plant Cell Physiology 48: 1724-1736. 
Krishnan VM \& Satakoppan VN (2009) Evaluation of growth parameters AGR, RGR and NAR of Soyabean [Glycine max L. Merr.] under Cd (II) stress. International Journal of Plant Science 4(2): 449-453.

Maliha R, Samina K, Najma A, Sadia A \& Farooq L (2004) Organic acids production and phosphate solubilization by phosphate solubilizing microorganisms under in vitro conditions. Pakistan Journal of Biological Sciences 7: 187-196.

Nadkarni AK (2005) Dr. K.M. Nadkarni'sIndian Materia Medica, Vol. 1.Bombay Popular Prakashan, Mumbai, India, pp. 1104-1106.

Nenwani V, Doshi P, Saha T \& Rajkumar S (2010) Isolation and characterization of a fungal isolate for phosphate solubilization and plant growth promoting activity. Journal of Yeast and Fungal Research 1(1): $9-14$.

Odee DW, Indieka SA \& Lesueur D (2002) Evaluation of inoculation procedures for Calliandra calothyrsus Meisn.grown in tree nurseries. Biology and Fertility of Soils 36(2): 124-128.

Pradhan P, Joseph L, Gupta V, Chulet R, Arya H, Verma R \& Bajpai A (2009) Saraca asoca (Ashoka): a review. Journal of Chemical and Pharmaceutical Research 1: 62-71.

Pushpangadan P, Mehrotra S, Rawat AKS, Tewari SK, Sikarwar RLS \& Misra N (2004) Package of practices for oganic cultivation of important medicinal plants, Part I. Economic Botany Information Service, National Botanical Research Institute, Lucknow, pp. 85.

Sharma PC, Yelne MB, Dennis TJ, Joshi A \& Billore KV (2005) Database on medicinal plants used in Ayurveda. Department of ISM \& H, Ministry of Health and Family Welfare, Govt. of India.

Vibha, Kumari G \& Nidhi (2014) Impact of phosphate solubilizing fungi on the soil nutrient status and yield mungbean (Vigna radiate L) crop. Annual Agriculture Research New Series 35(2): 136-143. 